\title{
SIMULTANEOUS RESPIRATORY EXCHANGE AND BLOOD SUGAR TIME CURVES OBTAINED IN DIABETIC AND NON DIABETIC INDIVIDUALS FOLLOWING INGESTION OF GLUCOSE
}

\author{
BY I. M. RABINOWITCH
}

With THE ASSistance of ALTHEA B. FRITH and ELEANOR V. BAZIN

(From the Department of Metabolism, the Montreal General Hospital, Montreal, Canada)

(Received for publication July 1, 1925)

\section{INTRODUCTION}

Hyperglycaemia and glycosuria result when the combined rates of oxidation and storage do not keep pace with the rate of absorption of glucose from the alimentary canal or its formation in the body. Carbohydrate tolerance is therefore usually estimated by the study of glycaemia and glycosuria. Another generally recognized, and probably more efficient method, is the study of the respiratory exchange. These procedures have, from time to time, depending upon the circumstances in any given case, been employed independently. It would appear, however, that a study combining both methods would be the most satisfactory.

Even in normal individuals simultaneous blood and respiratory metabolism data, obtained following the ingestion of glucose, are very scanty. In isolated instances in studying carbohydrate metabolism in diseases other than diabetes, such data have been obtained for comparative purposes. Of special note are those of Sanger and Hun (1) in their work on hyperthyroidism, and Linder, Hiller and Van Slyke (2) on nephritis. Finley and Rabinowitch (3) and more recently Ladd and Richardson (4) applied this method in a study of renal glycosuria.

The object of this paper is to record simultaneous respiratory exchange and blood sugar time curves obtained in five cases of renal glycosuria, eleven cases of diabetes of different severity, and two cases of pituitary disease with glycosuria. 
For the discussion of results it is necessary first to consider briefly the normal values obtained with the individual procedures. The literature of each method has frequently been reviewed and requires no repetition.

\section{BLOOD SUGAR}

In a comprehensive study, including a statistical analysis of 4000 individual determinations in 971 cases, Gray (5) presented the views now most generally accepted. The values of the mean and the mode (the most typical results) of the series agreed very closely. The blood sugar time curve is characteristic. The fasting blood sugar is about 0.09. Following the administration of glucose, the maximum increment is noted within 30 minutes, and the value is below 0.180 per cent, the average peak being 0.140 per cent. The rate of decline is at first more rapid, then slower. Within 3 hours the blood sugar concentration is equal to or below that of the fasting period.

In only ten of 431 cases was the fasting level above 0.12 per cent. Eight of these were 0.130 per cent. In one case it was 0.15 and in another 0.160 per cent. These data are of particular interest since, in the majority of cases (300 out of 479), the dose of sugar administered by the various workers was that now generally employed, namely, 70 to 100 grams. In the majority of the 300 cases abnormal glycosuresis did not occur. It was, however, found in a sufficient number, namely, 129, to emphasize the difficulty of the interpretation of this phenomenon.

The majority of observers are also in agreement as to the relation between the type of the curve and the dose of sugar given. With as little as $\mathbf{5}$ grams an appreciable increase was noted. The highest peak with the smallest dose was as great as the average peak with the larger dose. With doses exceeding 25 grams the peak was not affected. Increasing the dose merely prolonged the time necessary for the blood sugar to return to its original fasting level. The difference between the effects of the starches and glucose was too small to determine any special preference.

In diabetics (excluding hypertension, nephritis, hepatic disorders, hyperthyroidism, hyperpituitarism, etc.) the mean values corresponds to those now generally recognized. Following the administration of 
glucose the rate of increase of the blood sugar percentage is slower, and the peak occurs later (at the end of the first hour). The rate of return to the original level varies with the severity of the disease as indicated by the degree of hyperglycaemia in the post-absorptive state.

In renal glycosuria, in the absence of nephritis, the mean levels of the fasting blood sugar, the rate and the character of the curve of decline are essentially the same as those found in normal individuals.

\section{RESPIRATORY EXCHANGE}

The average respiratory quotient during the fasting period is 0.82 ( 0.83 for males and 0.81 for females) (6). After the administration of 100 grams of glucose an increase may be noted within 7 minutes (7) and rarely fails to occur within 30 minutes. The average maximum increase is about 0.12 (8). In some instances a slight decrease may be noted. In conditions which deplete glycogen, such as exercise, starvation, etc., no increase or an actual decrease may be noted for a time $(7,8,9)$. Benedict and Carpenter (8) found a fairly consistent picture in the ten cases observed. The lowest, highest and average peaks of carbon dioxide production were respectively 12,35 and 25 per cent above the basal period; of oxygen consumption, 3,22 , and 12 per cent; of the heat production 6, 24 and 14; and of the respiratory quotients, $0.07,0.17$ and 0.12 per cent. The average time of appearance of the maximum effects was within 2 hours.

Excluding the technical difficulties, psychic and other factors which may yield artificial respiratory quotients - common to both normal and diabetic subjects - and assuming that the quotients obtained approximate true metabolic respiratory quotients, there are still many factors which influence their value in the fasting state in diabetes and make difficult their interpretation. Rate of metabolism, composition of the diet of the previous day, the oxidation of acetone bodies, non-utilization of carbohydrates, incomplete oxidation of fats and decreased urea formation are some of these factors. The numerous vagaries have been discussed by both Joslin and DuBois in their recent monographs (10). It is therefore unnecessary to repeat these here.

Following the administration of glucose to a diabetic in the absence of insulin, three types of response may be noted: $(a)$ no increase, $(b)$ 
an increase, and in some cases approximating the response in normal individuals, and $(c)$ an initial decrease followed by an increase. All three types of response were found during thisinvestigation. These will be discussed separately, and then correlated with the clinical picture and blood sugar curves. The curve of the heat production may or may not parallel the curve of the respiratory quotient.

METHODS

\section{Classification of cases}

The diagnosis of all the cases of renal glycosuria was based upon the generally accepted clinical and laboratory standards, namely, (a) absence of hyperglycaemia, $(b)$ no uniform relation, between intake and excretion of sugar, $(c)$ excretion of sugar slight, $(d)$ normal blood sugar time curves following administration of glucose, and $(e)$ absence of other clinical signs and symptoms suggestive of the common type of diabetes. The important clinical index pointed out by Joslin, namely, the absence of diabetes following many years of observation, could for obvious reasons not be applied.

The classification of the diabetics into very mild, mild (incipient), moderate and severe, must, of necessity, be approximate. Joslin, though not strictly adhering to carbohydrate tolerance as a guide, does employ it. The individuals with a tolerance of less than 10 grams of glucose are regarded as severe, between 10 and 50 grams as moderate, and with a tolerance of $\mathbf{5 0}$ grams or over as mild. A classification based upon the use of insulin is suggested. According to Von Noorden's classification, those individuals are regarded as severe, who, in spite of a prolonged and extremely low carbohydrate diet, fail to become sugar free. Woodyatt ${ }^{1}$ suggests that the only rational method of measuring the degree of diabetes is to measure the velocity at which glucose can be utilized, that is, the number of grams utilized per unit of time such as 24 hours. The utilization of glucose equals the supply minus the excretion. The classification employed in this hospital, and for this investigation, combines that of Joslin and Von Noorden, with certain modifications. It is based upon $(a)$ glycosuria, $(b)$ ace-

${ }^{1}$ Personal communication. 
tonuria, in the absence of any previously restricted diet, $(c)$ clinical signs and symptoms, $(d)$ response to a "green day" diet, and $(e)$ composition of the final diet.

1. Very mild. The glycosuria is transient or post prandial only, and disappears readily with moderate change in diet, which includes eliminating the sugar in tea or coffee avoiding pastries and puddings, but allowing one ounce of bread at each meal. Otherwise no particular restriction is made as to meats, or vegetables. The glycosuria is discovered by routine examination, and there are no other signs or symptoms of diabetes.

2. Mild cases. The glycosuria is present throughout the day, but may be made to disappear in one or two days, following a "green day" diet, consisting of 15 grams of carbohydrates, 20 grams of fat and 25 grams of protein. These patients following a "ladder diet," eventually tolerate as much as $\mathbf{1 5 0}$ grams carbohydrates. Clinical signs and symptoms may or may not be present. In the absence of a previous restriction of diet the urine contains no acetone bodies.

3. Moderate. The glycosuria is persistent throughout the day. Acetone bodies are found in the urine in the absence of previous restriction in diet. Clinical signs and symptoms are more pronounced. The urine becomes sugar free following 3 to 4 "green" days. The final diet contains at least 50 grams of carbohydrates, 150 grams of fat, and 50 grams of protein.

No insulin is required to maintain the average weight for the height.

4. Severe. The patient does not become sugar free after 4 "green days." Acetone bodies in the urine are marked. The clinical symptoms are still more pronounced. Glycosuria persists throughout the "ladder" period, while the diet is approaching the basal requirements. Insulin is necessary with the final diet, to maintain the average weight for the height of the individual.

\section{LABORATORY TECHNIQUE}

All tests were performed in the morning. The respiratory quotient and basal metabolic rate were first obtained in the post-absorptive state, and after half an hour of complete muscular rest. Blood and urine specimens were then taken. The dose of glucose (dissolved in $150 \mathrm{cc}$. of water and flavoured with lemon juice) as indicated in the tables, was then given. The respiration experiments were of 10 minutes duration each, and commenced at such a time so that each period ended at the time recorded in any given case, namely, 30 minutes, 60 minutes, 1 hour, 2 hours, etc., following the ingestion of glucose. Blood and urine specimen were obtained at the end of each respiratory experiment. The Tissot gasometer and Haldane gas analysis apparatus were used. All gas analyses were made in dupli- 
cate by the same individual (E. V. B.). All blood and urine estimations were made by the same individual (A. B. F.). For the blood sugars the modified Myers-Benedict method was used: Urine sugars were estimated by the Benedict-Osterberg procedure after suitably diluting the specimens.

\section{CALCULATIONS}

In the cases of renal glycosuria, very mild - mild, and in some moderate cases of diabetes, a constant protein metabolism was assumed ( 15 per cent of the total). On this basis the non-protein respiratory quotients were calculated. In some moderate cases and in the severe type of diabetes associated with abnormal metabolism, nitrogen determinations were made by the Kjeldahl method, and thus non-protein respiratory quotients were obtained. From the non-protein respiratory quotient and the metabolic rate the calculations for the utilization of the carbohydrate were made in the usual manner. The nonprotein calories, assumed to be derived from the carbohydrates and fats, were apportioned according to the Zuntz-Schumberg Tables as modified by Williams, Riche and Lusk (11). The results are recorded in the accompanying tables. No alterations were made in the calculations where the respiratory quotients were greater than 1.0 or less than 0.70. In the former case, carbohydrate, and in the latter, fat oxidation, was assumed to be the only factor influencing the respiratory quotients.

\section{DISCUSSION}

The detailed data obtained from the cases of renal glycosuria are recorded in table 1. The average increment in carbon dioxide production was 26.4 'per cent; in oxygen consumption 9.6 per cent; in heat production 13. per cent; and in the respiratory quotient 0.11 . These data approximate very closely those obtained by Benedict and Carpenter on normal individuals. The average amount of glucose oxidized per hour for the first 2 hours was 11.99 grams. This also approximates very closely that recorded by Finley and Rabinowitch in one case of renal glycosuria (3) and other unpublished data obtained in normal individuals in this laboratory. The above data therefore, further strengthen the view that the glycosuria in this condition results 
from an undue permeability of the kidneys, the functions of oxidation and storage, unlike these in true diabetes, remaining unimpaired. In

TABLE 1

Simultaneous respiratory exchange and blood sugar time curves in cases of renal glycosuria

\begin{tabular}{|c|c|c|c|c|c|c|c|c|c|}
\hline : & 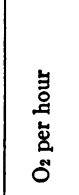 & 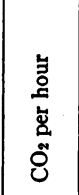 & 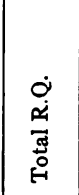 & 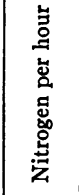 & 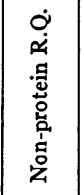 & 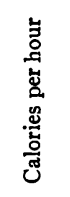 & 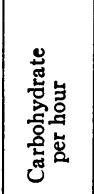 & 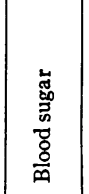 & Remarks \\
\hline minutes & liters & liters & & grams & & & grams & percent & \\
\hline $\begin{array}{c}\text { Basal } \\
30\end{array}$ & 16.58 & 11.87 & 0.716 & 0.474 & 0.698 & 77.8 & 0 & $\begin{array}{l}0.119 \\
0.166\end{array} \mid$ & $\begin{array}{l}\text { No. 1. Renal glycosuria; } 100 \\
\text { grams glucose }\end{array}$ \\
\hline 60 & 16.76 & 13.64 & 0.814 & 0.492 & 0.816 & 80.7 & 6.47 & 0.111 & \\
\hline $\begin{array}{l}120 \\
180\end{array}$ & 16.04 & 13.47 & 0.84 & 0.474 & 0.847 & 77.8 & 8.64 & $\left|\begin{array}{l}0.125 \\
0.087\end{array}\right|$ & \\
\hline $\begin{array}{c}\text { Basal } \\
30\end{array}$ & 11.64 & 8.95 & 0.769 & 0.338 & 0.761 & 55.5 & 2.31 & $\begin{array}{l}0.094 \\
0.144\end{array} \mid$ & $\begin{array}{r}\text { No. 2. Renal glycosuria. } \\
\text { (pregnancy); } 100 \text { grams }\end{array}$ \\
\hline 60 & 12.36 & 11.33 & 0.917 & 0.401 & 0.943 & 65.2 & 11.74 & 0.102 & glucose \\
\hline $\begin{array}{l}120 \\
180\end{array}$ & 13.24 & 12.03 & 0.909 & 0.398 & 0.931 & 65.4 & 11.29 & $\begin{array}{l}0.119 \\
0.068\end{array} \mid$ & \\
\hline $\begin{array}{c}\text { Basal } \\
30\end{array}$ & 12.48 & 8.78 & 0.704 & 0.357 & 0.683 & 58.5 & 0 & $\left|\begin{array}{l}0.103 \\
0.108\end{array}\right|$ & $\begin{array}{l}\text { No. } 3 . \text { Renal glycosuria; } 100 \\
\text { grams glucose }\end{array}$ \\
\hline 60 & 13.91 & 12.15 & 0.874 & 0.414 & 0.887 & 68.0 & 9.64 & 0.161 & \\
\hline 120 & 11.74 & 10.21 & 0.870 & 0.350 & $0.883 \mid$ & 57.4 & 7.70 & 0.120 & \\
\hline 180 & & & & & & & & 0.096 & \\
\hline $\begin{array}{c}\text { Basal } \\
30\end{array}$ & 16.50 & 11.74 & 0.712 & 0.473 & 0.692 & 77.4 & 0 & $\left|\begin{array}{l}0.074 \\
0.154\end{array}\right|$ & $\begin{array}{l}\text { No. 4. Renal glycosuria; } 100 \\
\text { grams glucose }\end{array}$ \\
\hline 60 & 18.85 & 14.89 & 0.790 & 0.550 & 0.787 & 90.3 & 5.85 & 0.159 & \\
\hline 120 & 18.86 & 15.40 & 0.817 & 0.554 & 0.821 & 91.0 & 8.00 & 0.099 & \\
\hline 180 & & & & & & & & 0.077 & \\
\hline $\begin{array}{c}\text { Basal } \\
30\end{array}$ & 17.84 & 13.05 & 0.732 & 0.512 & 0.716 & 84.1 & 0.266 & $\begin{array}{l}0.077 \\
0.123\end{array}$ & $\begin{array}{l}\text { No. } 5 . \text { Renal glycosuria; } 100 \\
\text { grams glucose }\end{array}$ \\
\hline 60 & 17.45 & 12.37 & 0.709 & 0.550 & 0.686 & 91.8 & 0 & 0.090 & \\
\hline 120 & 18.81 & 14.82 & 0.788 & 0.549 & 0.784 & 90.1 & 5.14 & 0.100 & \\
\hline 180 & & & & & & & & 0.085 & \\
\hline
\end{tabular}

one case (no. 5) there was noted a fall in the total respiratory quotient as late as 1 hour after the ingestion of glucose, and all the non-protein respiratory quotients were below 0.70 . It is thus assumed that no

THE JOURNAL OF CLINICAL INVESTIGATION, VOL. II, NO. 2 
carbohydrate was being oxidized during the period of investigation. This case is of particular interest. The fall in the respiratory quotient and the absence of oxidation of glucose may be attributed to the fact that the patient was in a state of carbohydrate starvation at the time of the test. Because glycosuria was found, the patient was apprehensive of his condition, and lived on a low carbohydrate diet for weeks prior to the test. The importance of recognizing this phenomenon in the interpretation of the results of blood sugar time curves in diabetes will be discussed later.

In table 2 are recorded the detailed data from the different types of cases of diabetes, very mild, mild, moderate and severe. Since the data of the individual subjects are so at variance with one another and the cases differed clinically, a study of average results would appear to be of little value. It will be noted that in all the cases the rate of utilization of glucose (grams in 2 hours), was much below the average found for normal individuals. There was, however, no perfect correlation between the rate of utilization and the severity of disease. An explanation of this is suggested in the following discussion.

In the majority of cases recorded in the literature no rise in the respiratory quotient is noted following the ingestion of glucose. This is naturally attributed to the inability of the diabetic to tolerate carbohydrates. It might be pointed out that no rise in the respiratory quotient may indicate defective oxidation. It does not, however, necessarily follow that there is also defective storage. Tolerance for carbohydrates includes both oxidation and storage. In the cases recorded here three different types of reactions to glucose ingestion, manifested in the respiratory quotient, are noted; namely, $(a)$ no response, $(b)$ an increment, and $(c)$ an initial decrement followed by an increment.

All the respiratory quotient curves and their corresponding blood sugar curves are recorded in table 3 . This is done with the object of correlation. Unexpected results were found. It will be noted that as late as at the end of one hour in the very mild (no. 6), in one mild (no. 7), and in two moderate (nos. 9 and 10) cases, there was an initial decrement in the respiratory quotient. On the other hand, in two of the three severe cases (nos. 14 and 15), a definite increment was noted. In both of the latter cases the heat production had also increased. 
TABLE 2

Simultaneous respiratory exchange and blood sugar time curves in cases of diabetes mellitus

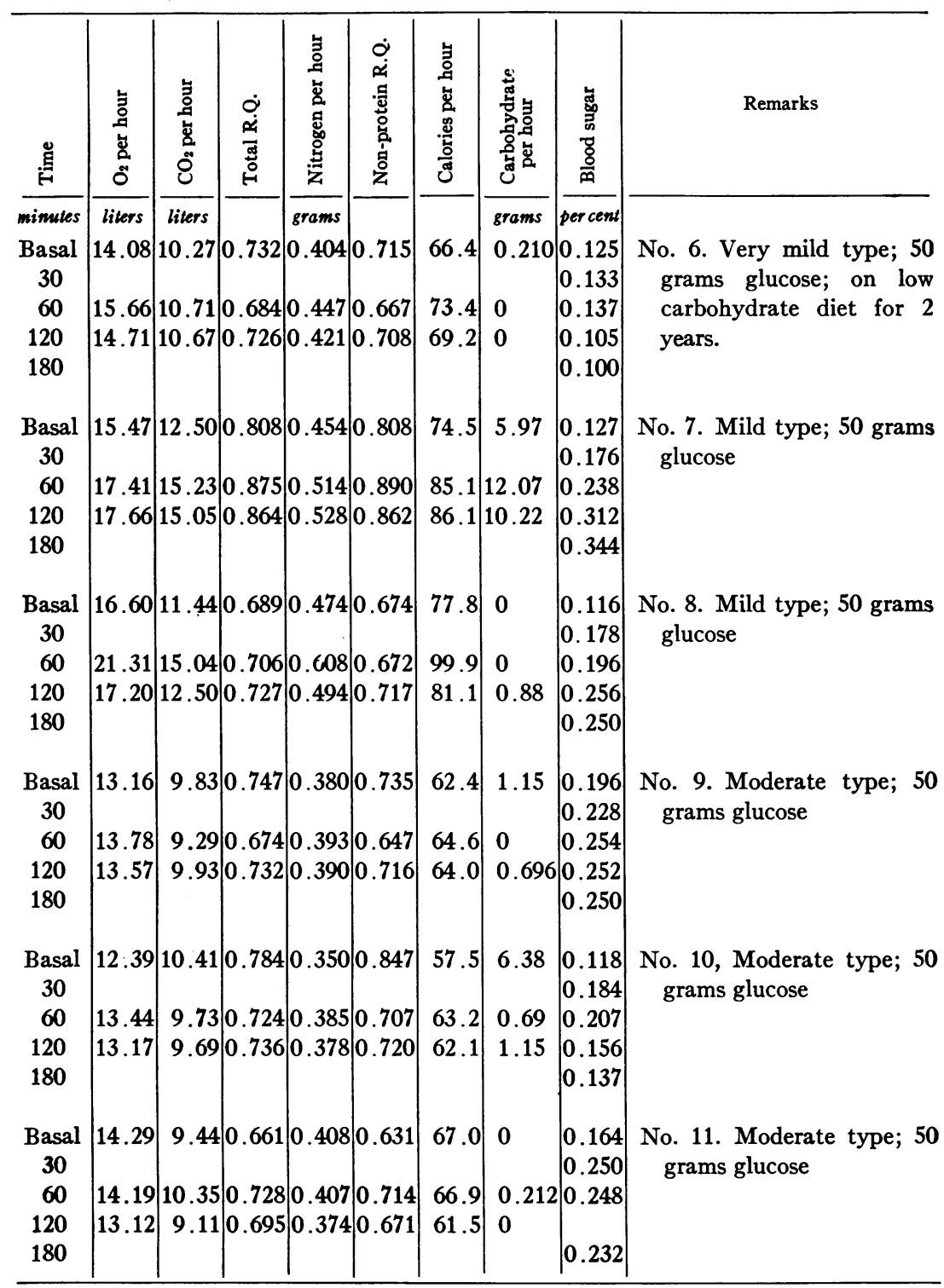




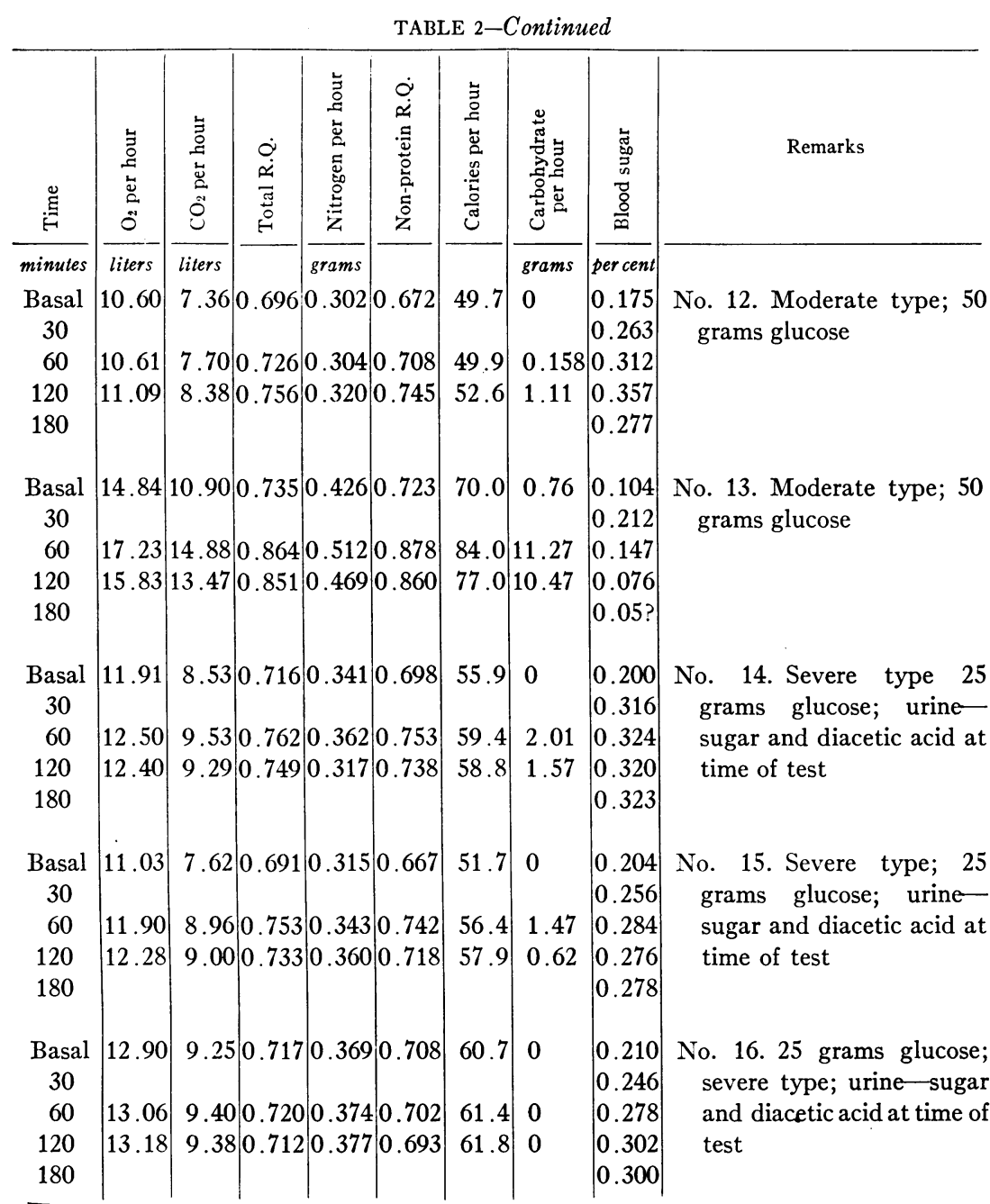

The subjects with severe diabetes were apparently oxidizing glucose, but in spite of this the blood sugars were increasing. It appears reasonable therefore, that the hyperglycaemia was due chiefly to defective storage. McCann and Hannon (11) in a study of the respiratory exchange alone, obtained similar results, and offered an explanation of this phenomenon. The data obtained in the cases recorded here, by a simultaneous study of the respiratory exchange and blood sugar, strengthen that view. 
There appear to be two different types of diabetics, namely, those who can store more readily than oxidize and those who can oxidize more readily than they can store. To the former group appears to belong the less severe type of the disease. It will be noted that the fall in the respiratory quotient was noted in the very mild, mild and moderate cases. The level to which the respiratory quotient may fall is striking. That such low quotients are no index of severity of the disease is further suggested from the fact that Benedict and Carpenter (8)

TABLE 3

Summary of respiratory quotient and blood sugar data

\begin{tabular}{c|c|c|c|c|c|c|c|c|l}
\hline $\begin{array}{c}\text { Case } \\
\text { num- } \\
\text { ber }\end{array}$ & \multicolumn{2}{|c|}{ Respiratory quotients } & \multicolumn{5}{|c|}{ Blood sugar per cent } & \multirow{2}{*}{ Remarks } \\
\hline & Basal & 60 & 120 & Basal & 30 & 60 & 120 & 180 & \\
\hline 1 & 0.716 & 0.814 & 0.840 & 0.119 & 0.166 & 0.111 & 0.125 & 0.087 & Renal glycosuria \\
2 & 0.769 & 0.917 & 0.909 & 0.094 & 0.144 & 0.102 & 0.119 & 0.068 & \\
3 & 0.704 & 0.874 & 0.870 & 0.103 & 0.108 & 0.161 & 0.120 & 0.096 & \\
4 & 0.712 & 0.790 & 0.817 & 0.074 & 0.154 & 0.159 & 0.099 & 0.077 & \\
5 & 0.732 & 0.709 & 0.788 & 0.077 & 0.123 & 0.090 & 0.100 & 0.085 & \\
6 & 0.732 & 0.684 & 0.726 & 0.125 & 0.133 & 0.137 & 0.105 & 0.100 & Very mild diabetic \\
7 & 0.808 & 0.875 & 0.864 & 0.127 & 0.176 & 0.238 & 0.312 & 0.344 & Mild diabetic \\
8 & 0.689 & 0.676 & 0.727 & 0.116 & 0.178 & 0.196 & 0.256 & 0.250 & \\
9 & 0.747 & 0.674 & 0.732 & 0.196 & 0.228 & 0.254 & 0.252 & 0.250 & Moderate \\
10 & 0.784 & 0.724 & 0.736 & 0.118 & 0.184 & 0.207 & 0.156 & 0.137 & \\
11 & 0.661 & 0.728 & 0.695 & 0.164 & 0.250 & 0.248 & $(?)$ & 0.232 & \\
12 & 0.696 & 0.725 & 0.756 & 0.175 & 0.263 & 0.312 & 0.357 & 0.277 & \\
13 & 0.735 & 0.864 & 0.851 & 0.104 & 0.212 & 0.147 & 0.076 & $(?)$ & \\
14 & 0.716 & 0.762 & 0.749 & 0.200 & 0.316 & 0.324 & 0.320 & 0.323 & Severe \\
15 & 0.691 & 0.753 & 0.733 & 0.204 & 0.256 & 0.284 & 0.276 & 0.278 & \\
16 & 0.717 & 0.720 & 0.712 & 0.210 & 0.264 & 0.278 & 0.302 & 0.300 & Pituitary disease, gly- \\
17 & 0.855 & 0.941 & 1.01 & 0.103 & 0.133 & 0.158 & 0.107 & 0.104 & Pitas \\
& & & & & & & & & cosuria \\
18 & 0.727 & 0.828 & 0.767 & 0.100 & 0.088 & 0.111 & 0.083 & 0.095 & \\
\hline
\end{tabular}

found such a decrease $(0.70$ to 0.67$)$ in a normal individual (B. M. K.), following the ingestion of 100 grams dextrose, and McCann (13) noted such a decrease $(0.72$ to 0.68$)$ in a normal individual after protein ingestion.

On the whole, no perfect correlation is noted between the respiratory quotient and blood sugar curves. This is to be expected. The type of respiratiry quotient curve obtained depends upon the character of the reaction to glucose ingestion, namely, storage or oxidation. 
Hyperglycaemia will result whether the disproportion is between the rate of absorption and oxidation or rate of absorption and storage.

A possible fallacy in the interpretation of blood sugar time curves is demonstrated in the very mild case. Here a perfectly normal blood sugar curve was found. The patient is known to be a diabetic. Because of his fear of the disease, he deliberately lives on a carbohydrate diet much below that prescribed, and has, therefore, very little store of glycogen. Following the ingestion of glucose, it was practically all stored. Not only was there no increase in the respiratory quotient, but a definite decrease ( 0.73 to 0.68$)$ was noted.

TABLE 4

Simultaneous respiratory exchange and blood sugar time curves in cases of pituitary disease

\begin{tabular}{|c|c|c|c|c|c|c|c|c|c|}
\hline 胥 & 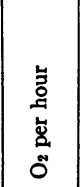 & 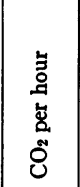 & 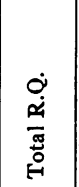 & 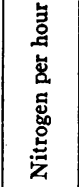 & 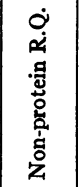 & 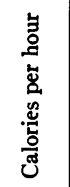 & 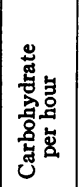 & 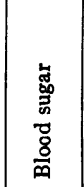 & Remarks \\
\hline minules & liters & liters & & grams & & & grams & percent & \\
\hline $\begin{array}{c}\text { Basal } \\
30\end{array}$ & 14.15 & 12.10 & 0.855 & 0.419 & 0.865 & 68.8 & 7.62 & $\begin{array}{l}0.103 \\
0.133\end{array}$ & No. 17.100 grams glucose \\
\hline 60 & 16.30 & 15.33 & 0.941 & 0.522 & 0.972 & 81.1 & 16.3 & 0.158 & \\
\hline 120 & 11.11 & 11.22 & 1.01 & 0.402 & 1.10 & 66.1 & 14.98 & 0.107 & \\
\hline 180 & & & & & & & & 0.104 & \\
\hline Basal & 11.39 & 8.28 & 0.727 & 0.328 & 0.711 & 53.8 & 0.17 & 0.100 & No. 18. 100 grams glucose \\
\hline 30 & & & & & & & & 0.088 & \\
\hline 60 & 12.44 & 10.30 & 0.828 & 0.367 & 0.833 & 60.2 & 5.75 & 0.111 & \\
\hline 120 & 13.76 & 10.55 & 0.767 & 0.400 & 0.758 & 65.6 & 2.53 & 0.083 & \\
\hline 180 & & & & & & & & 0.095 & \\
\hline
\end{tabular}

In two cases (table 4) of pituitary disease exhibiting glycosuria prior to the day of the test, the blood sugar time curves were of the normal type. Little comment appears necessary. In each case at the same time the respiratory quotient was increased following the ingestion of glucose. Since only a small portion of the glucose ingested was oxidized during the period of observation, and since during the same period the blood sugar was normal, the combined rates of oxidation and storage have kept pace with the rate of absorption, as would not be found in true diabetes. 


\section{SUMMARY}

Simultaneous respiratory exchange and blood sugar curves were obtained in eleven cases of diabetes mellitus, five of renal glycosuria and two of pituitary disease with glycosuria.

This method demonstrated the possible fallacy of the interpretation of blood sugar curves. Hyperglycaemia only results when the combined rates of oxidation and storage do not keep pace with the rate of absorption. In a mild diabetic in a state of starvation, the storage mechanism may be unimpaired, or at least not impaired enough to be demonstrated by methods now in use.

With the above data only and with methods presently available, it would be unwise to postulate several definite kinds of metabolic defects, since it is possible that all observed phenomena could be explained by assuming different degrees of one defect. The findings are, however, suggestive of the possible existence of two different forms of diabetes. In one form of the disease the predominant defect is storage of carbohydrates; in the other defective oxidation. Based upon the classification of diabetes employed here the former type of disturbance, namely defective storage, would appear to be predominant in the more severe form of the disease.

\section{BIBLIOGRAPHY}

1. Sanger, B. T., and Hun, E. G.: Arch. Int. Med., 1920, xxx, 397. The Glucose Mobilization Rate in Hyperthyroidism.

2. Linder, G. C., Hiller, A., and Van Slyke, D. D.: Jour. Clin. Invest., 1925, i, 247. Carbohydrate Metabolism in Nephritis.,

3. Finely, F. G., and Rabinowitch, I. M.: Quart. Jour. Med., 1924, xvii, 260. Renal Glycosuria.'

4. Ladd, W. S., and Richardson, H. B.: Jour. Biol. Chem., 1925, lxiii, 681. Clinical Calorimetry.

5. Gray, H.: Arch. Int.Med., 1923, xxxi, 241. Blood Sugar Standards.

6. Benedict, F. G., Emmes, L. E., Roth, P., and Smith, H. M.: Jour. Biol. Chem., 1914, xviii, 139. The Basal and Gaseous Metabolism of Normal Men and Women.

7. Higgins, H. L.: Amer. Jour. Physiol., 1916, xli, 258. The Rapidity with Which Alcohol and Some of the Sugars May Serve as Nutriment.

8. Benedict, F. G., and Carpenter, T. M.: Carnegie Inst. Wash. Pub. No. 261, 205. Food Ingestion and Energy Transformations.

9. Bernstein and Falta: Quoted by McCann. 
10. Joslin, E. P.: The Treatment of diabetes, Philadelphia, 1924, 3rd ed., 254. DuBois E. F. Basal Metabolism in Health and Disease. Philadelphia, 1924, 193.

11. Williams, H. B., Riche, J. A., and Lusk, G.: Jour. Biol. Chem., 1912, xii, 349. Animal Calorimetry.

12. McCann, W.S., and Hannon, R. R.: Bull. Johns Hopkins Hosp., 1923, xxxiv, 73. Studies of Diabetes Mellitus.

13. McCann, W. S.: Pro. Soc. Exp. Med. and Biol., 1919-20, xvii, 173. An Observation of the Effect of a Protein Meal Given to a Man at the End of an Eight-day Fast. 